\title{
ANS - Qualificação da Saúde Suplementar: equívocos na comparabilidade
}

Tânia Kadima Magalhães Ferreira; André Luiz Fernandes Mascarenhas; Maria Amélia Matos Nicolau de Lima; Adriane de Oliveira Sales; Angela Leal Faoro

\section{Introdução}

índices, conjunto de dados seguros/válidos, que devem ser mantidos no mínimo por 3 anos para alcançar o objetivo de comparabilidade. Rácio, relação entre duas grandezas (valor absoluto ou percentagem), visando identificar aspectos da gestão: facilidade/rapidez de cálculo; comparabilidade intra/inter empresas; utilização informação acessível; possibilidade conclusões imediatas.

Objetivo: analisar coerência Indicadores de Desempenho da Saúde Suplementar (IDSS) com literatura.

Metodologia: pesquisa IDSS e ANS (2015/2018).

\section{Resultados:}

1) indicadores/pesos sofreram e sofrem alterações anuais, impossível comparabilidade período mínimo de 3 anos, conforme literatura específica; 2) enviesamento avaliações de autogestões (sem fim lucrativo e peculiaridades de assistidos) com mesmos critérios das demais operadoras de mercado; 3 ) porte operadora não levado em conta, por isso resultado da avaliação não condiz com a realidade (impacto de uma reclamação em operadora de pequeno porte gera classificação no nível 3 no monitoramento da garantia de atendimento, o que não é razoável); 4) modalidade da operadora e perfil da população não considerados; consultas realizadas por médicos particulares, sem conhecimento da operadora, levam entendimento ANS que não houve atendimentos; 5) Agência não prevê liberdade de escolha dos beneficiários, confundindo privado com público: interferência na escolha do atendimento (tipo de parto; generalista x especialistas).

\begin{tabular}{|c|c|c|c|c|c|}
\hline \multicolumn{6}{|c|}{1 - INDICADORES E PESOS DA DIMENSÃO QUALIDADE EM ATENÇÃO À SAÚDE - IDQQS } \\
\hline PESO DA DTMENÃ̃O IDQS (\%) & & $40 \%$ & $25 \%$ & $25 \%$ & $30 \%$ \\
\hline Parto Adequado & 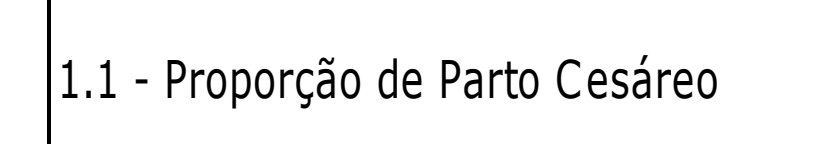 & 3 & 3 & 3 & 3 \\
\hline Atenģão ao Pré-Natal & $\begin{array}{l}\text { 1.2- - Taxa de Consultas de Pré- } \\
\text { Natal }\end{array}$ & - & - & . & 2 (novo) \\
\hline $\begin{array}{l}\text { Preventivo de câncer de colo do outero } \\
(2)\end{array}$ & $\begin{array}{l}1.3 . \text { Taxa de Citiopatologia Cérico- } \\
\text { vaginal Oncótica }\end{array}$ & 3 & 2 & 2 & 2 \\
\hline Fratura em Idosos & $\begin{array}{l}\text { l.1. - Taxa de Internaçă por } \\
\text { Fratura de Fênur em Idosos }\end{array}$ & 0 & 3 & 3 & 2(REDuç̄o) \\
\hline Cuidado Integral do Idoso & 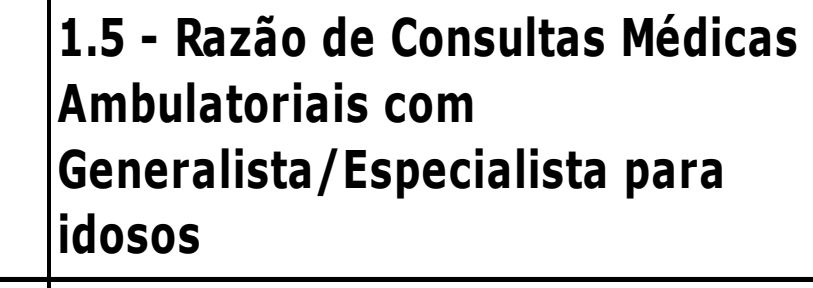 & & & - & 3(Novo) \\
\hline $\begin{array}{l}\text { Cuidado Integral da Crianga ate os } 4 \\
\text { anos }\end{array}$ & 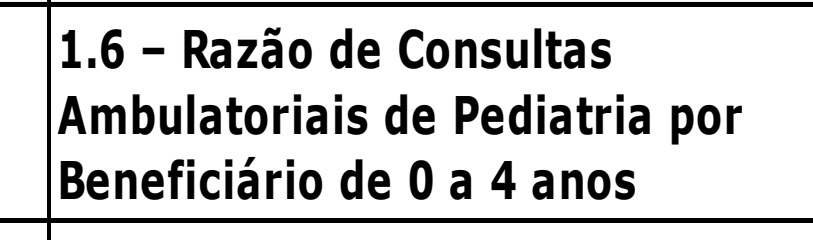 & & - & - & 2 (novo) \\
\hline Cuidado ao Diabético & $\begin{array}{l}\text { 1.7. - Taxa de Exames de } \\
\text { Hemoglobina Glicada }\end{array}$ & & - & . & 3 (Novo) \\
\hline Taxa de Mamografia (2) & & 3 & 2 & 2 & REtTRADO \\
\hline $\begin{array}{l}\text { Proporçăo de consulta Médica em } \\
\text { Pronto socorro }\end{array}$ & & 2 & 0 & RETRADO & RETRADO \\
\hline 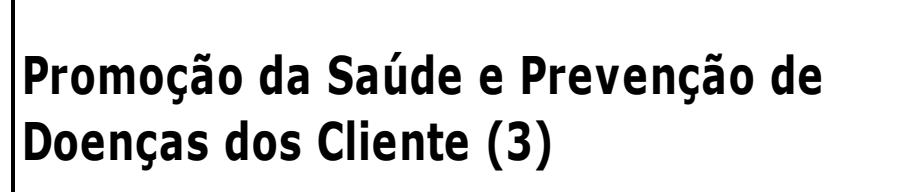 & 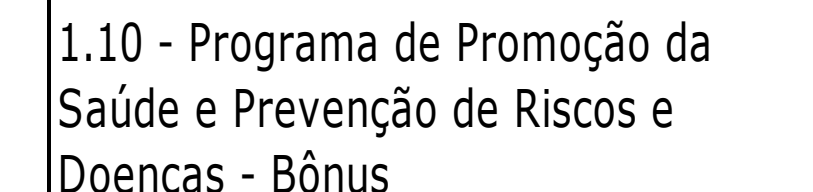 & $\begin{array}{l}\text { Bônus de } 10 \% \text { ou } 15 \% \\
\text { sobre IDQS }\end{array}$ & 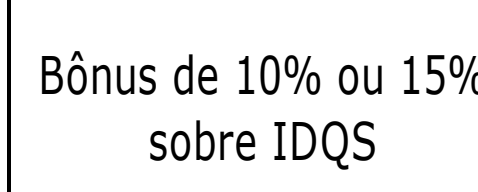 & $\begin{array}{l}\text { Bônus de 10\% ou } 15 \% \\
\text { sobre IDQS }\end{array}$ & $\begin{array}{l}\text { Bônus de 10\% ou } 15 \% \\
\text { sobre IDQS }\end{array}$ \\
\hline 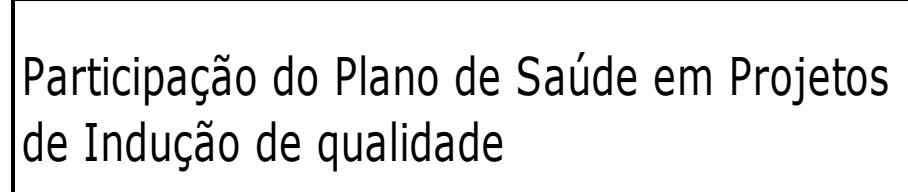 & 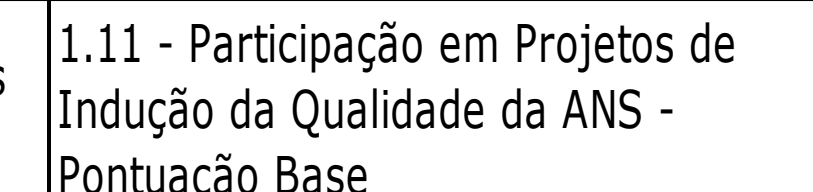 & & - & $\begin{array}{l}\text { Pontuagéb base de } \\
0,15 \text { a l Dops }\end{array}$ & $\begin{array}{l}\text { Pontucăăa Base de } \\
0,15 \text { na IDQ⿻日 }\end{array}$ \\
\hline
\end{tabular}

\begin{tabular}{|c|c|c|c|c|c|}
\hline \multicolumn{6}{|c|}{3 - INDICADORES E PESOS DA DIMENSÃO SUSTENTABILIDADE NO MERCADO - IDSM } \\
\hline PESO DA DIMENSÃO IDSM(\%) & & $20 \%$ & $25 \%$ & $25 \%$ & $30 \%$ \\
\hline Solidez do s seu Plano de Saúde & 3.1- - indice de Recursos Próprios & & 3 & 3 & 3 \\
\hline Resolusăga de Quvexaxas do cliente & 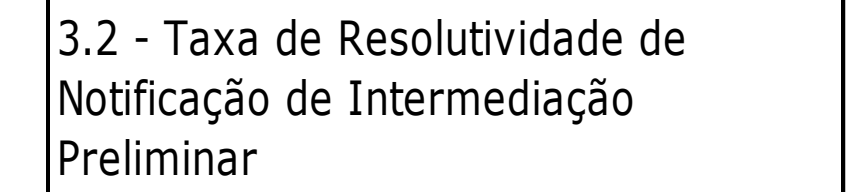 & & 2 & 2 & 2 \\
\hline Reclamaçöes Gerais do Cliente & 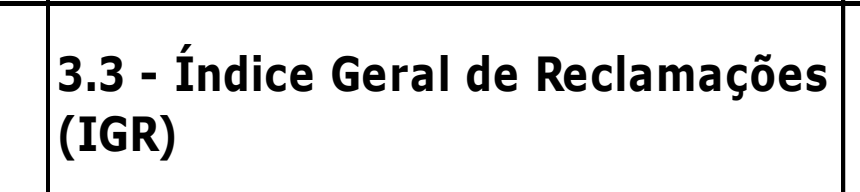 & 3 & RETTRADO & REtTRADO & 1 (REATIVADO) \\
\hline Taxa de Fiscalização & & 1 & 2 & 2 & RETTRADO \\
\hline Disponibilidade Financeira & & & 3 & 3 & RETTRADO \\
\hline 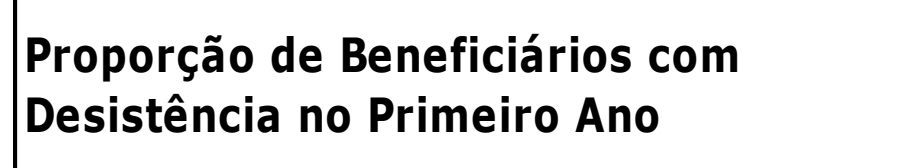 & & 1 & 1 & RETTRADO & Rettrado \\
\hline $\begin{array}{l}\text { Patrimonini Liauido ajustado pela Margem de } \\
\text { Solvencia }\end{array}$ & & ${ }^{2}$ & RETTRADO & REtTRADO & RETTRAD \\
\hline Liquidez Corrente & & 1 & RETTRADO & REtTRAdO & RETTRADO \\
\hline $\begin{array}{l}\text { Provisẵo de Eventos Ocorridose Nẵo } \\
\text { Avisados }\end{array}$ & & ${ }^{2}$ & RETTRADO & REtrRADO & RETTRAD \\
\hline $\begin{array}{l}\text { Suruciênncia em Ativos Garantidores } \\
\text { Vinculdos }\end{array}$ & & ${ }^{2}$ & REtTRADO & REtTRADO & RETTRADO \\
\hline Preso do Plano de Saúde & 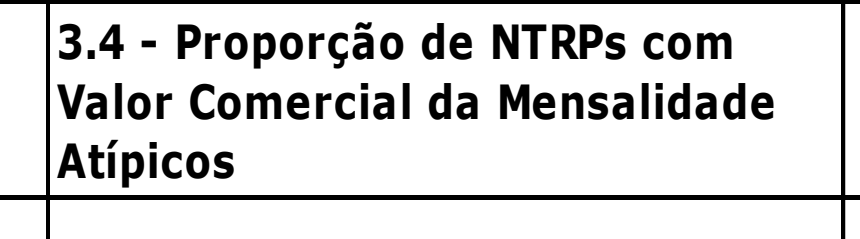 & & - & - & 1 (novo) \\
\hline Satisfaçăo do Cliente/Paciente & $\begin{array}{l}\text { 3.5. - Pesquisa de Satisfacāo do do } \\
\text { Beneficicario - Pontuaço base }\end{array}$ & & & & $\begin{array}{l}\text { Pontuacáa Base de } \\
0,25 \text { da a DOSM } \\
\text { (Novo) }\end{array}$ \\
\hline Gestấ Financeira Ativa & 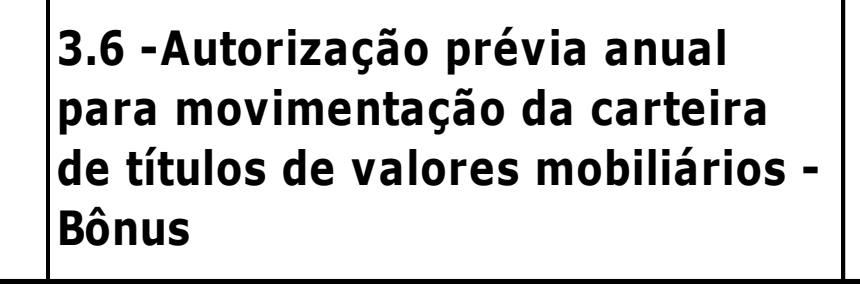 & & - & 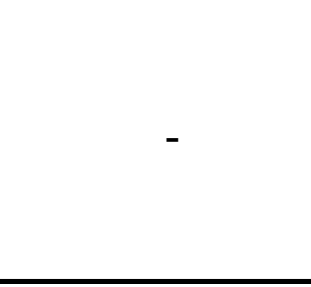 & 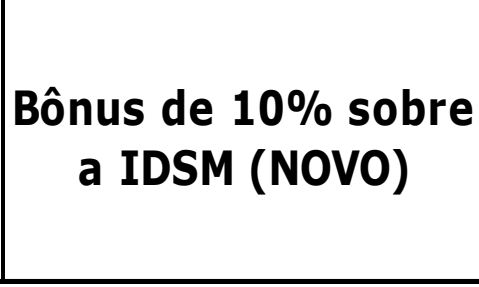 \\
\hline
\end{tabular}

\begin{tabular}{|c|c|c|c|c|c|}
\hline \multicolumn{6}{|c|}{2 - INDICADORES E PESOS DA DIMENSÃO GARANTIA DE ACESSO - IDGA } \\
\hline PESO DA DIMENSĀO IDGA (\%) & & $20 \%$ & $25 \%$ & $25 \%$ & $30 \%$ \\
\hline Renal Crônico & 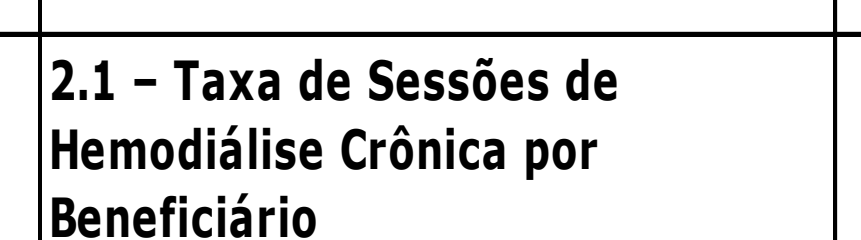 & & & & 1 (Novo) \\
\hline Médico de Refereñncia do Idoso(1) & $\begin{array}{l}\text { 2.2. - Taxa de Consultas Médicas } \\
\text { ambulutariais com Generalista } \\
\text { por Idosos }\end{array}$ & 3 & 1 & 2 (ALteraç̄o) & 3 (ALtteAaĞä) \\
\hline $\begin{array}{l}\text { Número de Consultas Medicas } \\
\text { Ambulatoriais por Beneficiário (!) }\end{array}$ & & 2 & 1 & 1 & RETRADO \\
\hline Taxa de Internaçăo Hospitalar (1) & & 2 & 1 & 1 & RETRADO \\
\hline $\begin{array}{l}\text { Indice de Sessoese Quiomioterapia } \\
\text { Sistêmica por Consulta Medica }\end{array}$ & & 2 & 2 & RETTRADO & RETRADO \\
\hline 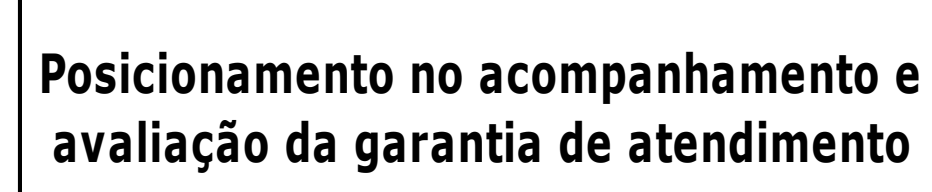 & & & - & 3 & RetrRADO \\
\hline Acesso a urgência E Energeñncia & 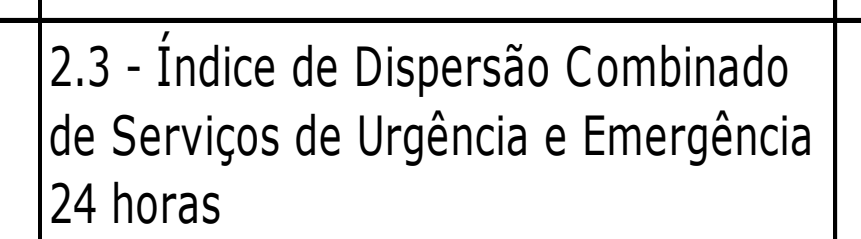 & 1 & 1 & 1 & 1 \\
\hline 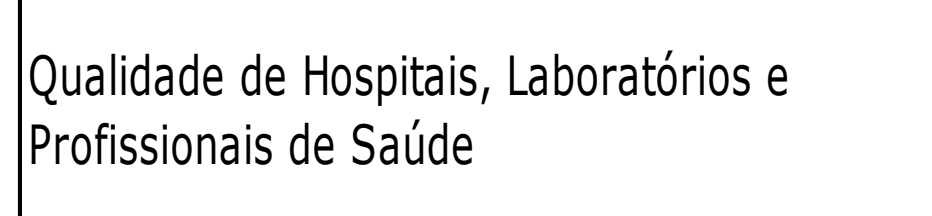 & 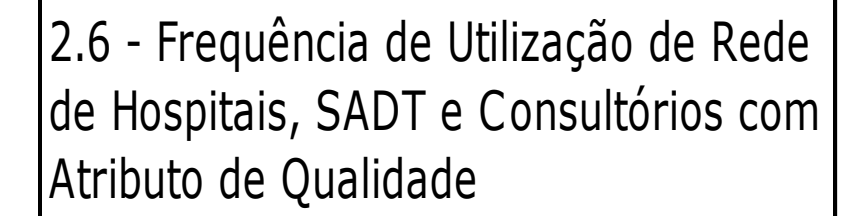 & 1 & 1 & 1 & 1 \\
\hline
\end{tabular}

\begin{tabular}{|c|c|c|c|c|c|}
\hline \multicolumn{6}{|c|}{4 - INDICADORES E PESOS DA DIMENSÃO GESTÃO DE PROCESSOS E REGULAÇÃO - IDGR } \\
\hline ESO DA DIMENSĂO IDGR(\%) & & $20 \%$ & $25 \%$ & $25 \%$ & $100 \%$ \\
\hline $\begin{array}{l}\text { ualidade do Dados do Cadastro do } \\
\text { einte }\end{array}$ & $\begin{array}{l}\text { 4.1. - Índice composto de } \\
\text { Qualidade Cadastral (SIB) }\end{array}$ & 3 & 1 (ALTERADO) & 2 (ALTERADO) & 2(ALTERAD) \\
\hline $\begin{array}{l}\text { dice de Regularidadede de envio dos } \\
\text { stemas de Informaçáo }\end{array}$ & & 3 & 1 ( ALTERADO) & 1 (ALTERADO) & RETIRADO \\
\hline $\begin{array}{l}\text { tilizacăo do Sus por Cliente de Plano } \\
\text { S Saude }\end{array}$ & 4.2. Taxa de utilizaçăo do sus & & 2 & 2 & 1 (ALTERADO) \\
\hline $\begin{array}{l}\text { ualidade da Informaçao em Saúde } \\
\text { viada para a ANS }\end{array}$ & 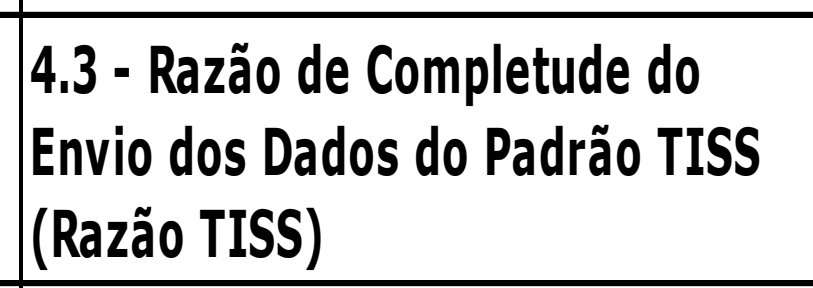 & & & Bônus de 10\% & 2(ALTERADO) \\
\hline 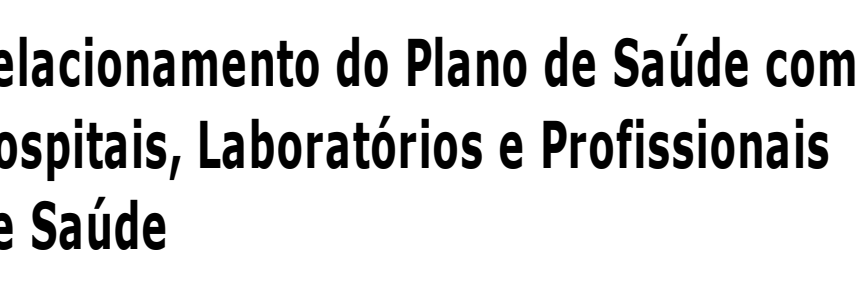 & 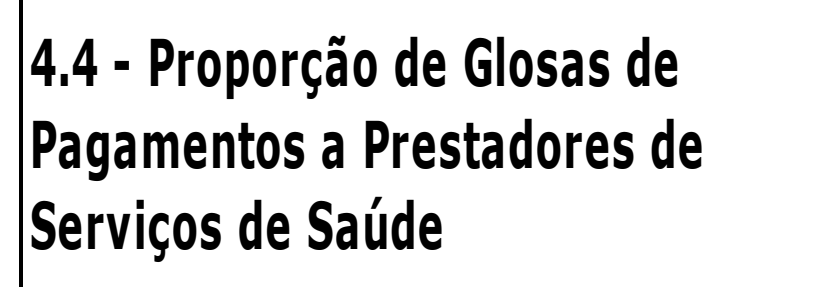 & & & & 1 (NOVO) \\
\hline 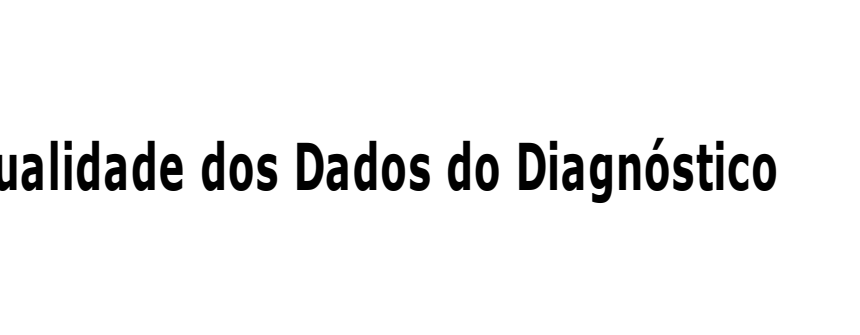 & 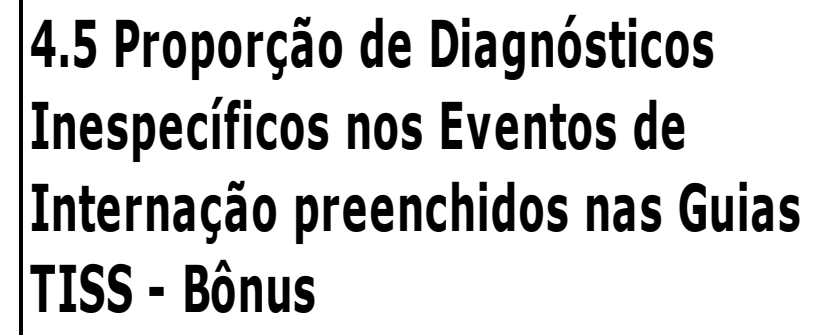 & & & & $\begin{array}{l}\text { Bônus de 10\% sobre } \\
\text { a IDGR (NOVO) }\end{array}$ \\
\hline
\end{tabular}

Conclusão: Indicadores/pesos precisam ser consistentes e abranger mínimo de 3 anos para que comparabilidade produza conclusões sustentadas e seguras, e informe ao consumidor real situação das operadoras. Entendemos ser necessário que o benchmarking ocorra em termos de médias setoriais, consideradas comparáveis e de referência (mesma modalidade e porte), visando correta identificação da posição relativa da empresa analisada, e evolução ao longo do tempo. Índices influenciados por fatores culturais e socioeconômicos causam distorção/vieses insustentáveis (repetidos anualmente), por isso entendemos devam ser excluídos da avaliação. Necessária avaliação programas de prevenção por impacto (médicos por indicadores).

Bibliografia: Fitz-enz,J. 2001. Retorno do Investimento em Capital Humano; Mota, A.G, Custódio, C. 2012. Finanças de empresas. Portugal: bnomics. 